\title{
Understanding induced abortion: Findings from a programme of research in Rajasthan, India
}

Population Council

Follow this and additional works at: https://knowledgecommons.popcouncil.org/departments_sbsr-rh

Part of the Family, Life Course, and Society Commons, International Public Health Commons, and the Maternal and Child Health Commons

How does access to this work benefit you? Let us know!

\section{Recommended Citation}

"Understanding induced abortion: Findings from a programme of research in Rajasthan, India," research brief. New Delhi: Population Council, 2004. 


\section{UNDERSTANDING INDUCED ABORTION: Findings from a programme of research in Rajasthan, India}

In India abortion has been legal for over 30 years following the enactment of the Medical Termination of Pregnancy (MTP) Act in 1971 (Government of India 1971). While the MTP Act permits abortion for a broad range of social and medical reasons, it also includes provisions regarding the delivery of services that have proved to constrain access to safe and legal abortion for the great majority of women in India.

Only doctors practising allopathic medicine who are trained in gynaecology or have undergone a government-sanctioned training in pregnancy termination can legally perform abortions. Additionally, abortions can only be provided at public facilities (at the primary health centre level and above) or at private facilities that have been certified by the government. Finally, abortions performed between 12 and 20 weeks' gestation require approval from two providers.

Due in part to these constraints, upto 90 percent of the six million induced abortions estimated to occur annually in India are illegal — provided in uncertified settings and/or by uncertified providers (Chhabra and Nuna 1994). While some of these illegal abortions are safe, many are unsafe and result in significant morbidity and mortality (Ganatra et al 1998; Johnston 2001; Sood et al 1995; Johnston 2002).

Available data suggest that the situation is particularly poor in the less-developed states of north India, including Rajasthan. Indeed, Rajasthan has high rates of unwanted fertility and unmet need for family planning, coupled with low contraceptive prevalence rates (IIPS and ORC Macro 2000)_factors that taken together suggest that the demand for abortion is likely to be high. Yet with a per capita availability of legal abortion services of one per 157,354 individuals, access to safe abortion in Rajasthan is limited (Johnston 2002). Most of the estimated 352,000 induced abortions every year in the state are performed illegally by uncertified medical or non-medical practitioners (Chhabra and Nuna 1994). Thus, by implication, Rajasthan is among the states in India where increased access to safe abortion services is most needed.

\section{The project}

Recognising this situation, the Population Council, in partnership with the Centre for Operations Research and Training and Ibtada (see box), undertook a programme of research on unwanted pregnancy and induced abortion in six purposively selected districts of Rajasthan-Alwar, Bikaner, Bhilwara, Karauli, Pali and Tonk. The programme was designed as a complement to service-delivery activities being undertaken by Parivar Seva Sanstha (see box), a national non-governmental reproductive health service provider, and aimed to provide comprehensive data on abortion to guide future programmes and policies. Under this programme, three studies were conducted from 2001 to 2002:

- A qualitative exploration of attitudes and behaviours surrounding unwanted pregnancy and induced abortion.

- A community-based survey of knowledge, attitudes and practices regarding unwanted pregnancy and induced abortion among evermarried women of reproductive age $(n=3,266)$ and a sub-sample of their husbands $(n=602)$.

- A situation analysis of abortion services (certified and uncertified) in both the formal ( $\mathrm{n}=105$ facilities; $n=119$ providers) and informal sectors ( $n=489$ providers). 


\section{Key findings}

\section{Prevalence of induced abortion and unwanted pregnancy}

A fairly significant proportion of women in the community-based survey -13 percent experienced at least one abortion. Abortion levels were particularly high among urban women (17 percent), as well as those who were literate (18 percent) or residing in a household with a high standard of living (19 percent). Abortions occurred largely to limit (77 percent) or space (22 percent) childbearing. Very few women (3 percent) reportedly had abortions because they desired a child of a different sex. Besides those women who underwent abortions, a fair number of others experienced unwanted pregnancies that were carried to term.

\section{Treatments and providers}

Data from this programme confirm that abortion is often a process that entails the consumption of home remedies, as well as the use of services in the informal and formal sectors. Twenty percent of women with successful abortions in the community-based survey reportedly used a home remedy or obtained services from an informal provider in an initial attempt to terminate their pregnancies. Both the qualitative study and the situation analysis show that a vast array of informal providers are used for abortion at the community level, including chemists, vaidhs, dais, and auxiliary nurse midwives. The majority (75 percent) of informal providers who participated in the situation analysis acknowledged providing women with tablets to provoke abortions, but generally reported low success rates of around 41 percent.

Not surprisingly, then, the majority ( 89 percent) of women with successful abortions in the community-based study eventually sought services from the formal sector. Private-sector doctors were used by 43 percent of those women, while the rest used public-sector providers. As almost two-thirds (65 percent) of privatesector facilities and 58 percent of public-sector facilities in our situation analysis were not certified to provide abortions under the MTP Act, however, many of the abortions obtained by the women in our community-based survey were likely to have been illegal.

\section{Quality of care}

Data from the situation analysis also suggest that the quality of care in abortion services, particularly in the public sector, is also poor. Indeed, the majority of formal-sector abortion providers interviewed in the situational analysis used outdated techniques to perform surgical abortions, such as dilatation and curettage. The easier and safer techniques of electric and manual vacuum aspiration were reportedly used far less frequently, even for abortions at the earliest gestational ages.

\section{Access to care}

Despite a government commitment to increase access to abortion services in rural areas, only five percent of rural women with abortions in the communitybased study availed of services in their own villages. One-quarter (24 percent) traveled over one hour to reach an abortion provider. Further evidence of poor access to abortion services in rural areas comes from the situation analysis, which found that among all of the primary and community health centres identified in the study area, only 21 and 65 percent, respectively, offered abortion services.

Additional financial and social barriers to care were identified in the studies. Although provisions for free MTP services exist in the public sector, all women reporting abortions in the community-based study incurred at least some out-of-pocket costs. In many cases (34 percent), those costs were well over 500 Indian Rupees. Formal providers in the situation analysis reported mean costs of 318, 497 and 750 Indian Rupees, respectively, for early firsttrimester, late first-trimester and second-trimester abortions, suggesting that formal-sector services are likely to be out of reach for many poor women faced with unwanted pregnancies. The situation analysis also showed that facilities routinely refuse to perform abortions in a number of circumstances, including if the women presents alone ( 72 percent), is married but nulliparous (53 percent) or is unmarried (37 percent), thus severely compromising women's reproductive rights.

\section{Post-abortion experiences}

Important problems in the quality of postabortion care emerged in both the communitybased study and the situation analysis. Post-abortion contraceptive counselling appears 
to be absent altogether, ineffectively conducted or coercive. Indeed, while most women obtaining abortions in the community-based study desired to limit or space their childbearing, the majority (60 percent) of them, particularly in rural areas (83 percent), did not receive any information or counselling regarding family planning.

Conversely, despite the removal of contraceptive targets from the Family Welfare Programme, 42 percent of formal providers interviewed in the situational analysis reported insisting on the adoption of a contraceptive method after abortion, with even a greater proportion (53 percent) doing so in the public sector. Not surprisingly, then, when women from the community-based study did adopt a method of family planning after their abortions, use was short-lived in 17 percent of cases.

Levels of post-abortion morbidity were relatively modest in our community-based study, with very little difference in urban and rural areas. Among those women who reported a problem after their abortions, however, most ( 83 percent) needed rest for atleast one day and could not undertake routine household chores ( 83 percent). Nearly half (45 percent) of all women and approximately twothirds (64 percent) of rural women with postabortion complications sought formal treatment for them and a fair number (13 percent) were

hospitalised, suggesting that when complications do occur they are likely to be severe, particularly in rural areas. Yet, counselling for potential complications may not be comprehensive. While the majority ( 89 percent) of formal providers in the situation analysis reported advising women to return immediately in the event of excessive bleeding following an abortion, far fewer said they recommend that women seek care in the case of severe abdominal pain or distension (49 percent), fever (36 percent) or foul-smelling discharge (20 percent).

\section{Spousal and family involvement in abortion}

Husbands and family members play a significant role in the abortion process. More than half (55 percent) of women with abortions in the community-based study reported that their husbands participated in the decision to seek an abortion and an additional 25 percent said that their spouses were solely responsible for the decision. Husbands (46 percent) and other family members (40 percent) also often participated in the selection of a provider for many women seeking abortions in the communitybased study.

While the MTP Act does not mandate a husband's consent, both the community-based study and the situation analysis show that it is a common practice. Eighty percent of women with induced abortions in the community-based survey indicated that their provider required such consent in order to perform the procedure. Similarly, according to the situation analysis, about half of all sampled facilities routinely obtain unnecessary consent from husbands and other family members. Additional data from the situation analysis suggests that this practice may result from misinformation regarding the MTP Act among formal providers, as 55 percent believed incorrectly that a husband's consent pre-abortion is mandated by law. While providers may demand spousal consent, however, men and women clearly preferred otherwise. Over half of all men (56 percent) and women (54 percent) in the communitybased study indicated that the absence of spousal consent requirements would be very important when selecting an abortion provider.

\section{Knowledge of the legality of abortion}

Knowledge of the legality of abortion at the community level was very low. Only 16 percent of men and 17 percent of women in the communitybased survey knew that abortion is legal in India. Rural women (13 percent) were particularly unlikely to be aware of their legal right to abortion. Similarly, only 29 percent of informal providers interviewed in the situation analysis knew that abortion is legal. While formal-sector providers interviewed in the situation analysis were well aware of the majority of circumstances under which abortion is legal in India, 30 percent of them believed incorrectly that abortion is illegal among unmarried women.

\section{Conclusion}

The key message that emerges from these studies is that the legal right to abortion is not a reality for the majority of women in our sample in Rajasthan more than 30 years following the legalisation of abortion in India. The ineffective implementation of the law and the poor quality of care in existing abortion services are evident in the distances women travel to reach

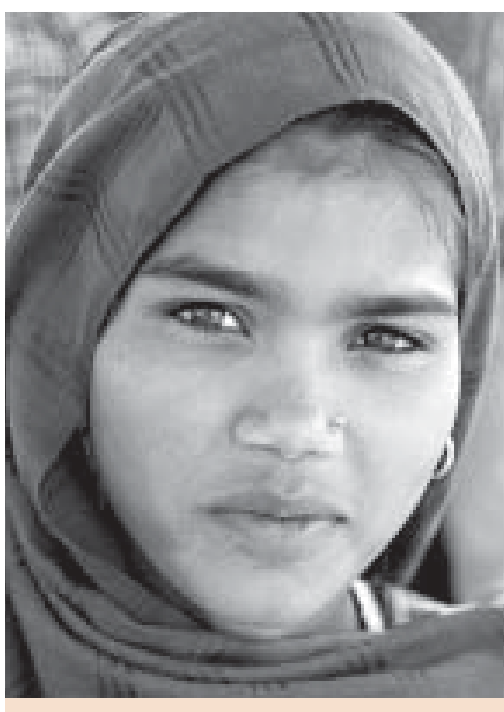

Parivar Seva Sanstha is a national non-governmental organisation providing reproductive health services with an emphasis on family planning. Registered in 1978 , the organisation today has a strong network of $\mathbf{4 0}$ reproductive health clinics, a contraceptive products marketing and distribution system, and numerous projects and outreach activities located in $\mathbf{2 1}$ states of India.

The Centre for Operations Research and Training (CORT) is a leading multidisciplinary social science research and training organisation with headquarters in Vadodara, Gujarat. Over the last 13 years it has undertaken diagnostic, evaluation and operations research on various components of reproductive health, population, women and other social issues.

Ibtada is a non-profit, nongovernmental development organisation working to uplift the rural poor and deprived in Rajasthan and adjoining states. The organisation was registered in 1997 when the founder Executive Director was conducting a benchmark survey of the Mewat region for the Government of Rajasthan which highlighted the backwardness of the region and thus led to the initiative called Ibtada, an Urdu word meaning the beginning. 
services, the charges they pay to end their pregnancies, the widespread practice of obtaining spousal consent for abortion, the lack of any and/or effective counselling regarding post-abortion methods of family planning, and the continued low levels of familiarity with the legality of abortion. These studies also vividly highlight that women have strong desires to meet their reproductive intentions and that existing methods of family planning and abortion services are failing them.

\section{Recommendations}

\section{Policy}

- Recent amendments in the MTP Act mark an important effort to improve access to legal, affordable, high quality abortion services. Further efforts are needed, however, to ensure meaningful access to abortion in India. While the decentralisation of the facility certification process to the district level is likely to increase the number of certified facilities, other issues may need to be addressed or clarified in order to encourage uncertified facilities to comply with legislative requirements. Future policy discussions should also consider the feasibility of alternative mechanisms for uncertified providers, including those trained in Indian systems of medicine, to obtain and demonstrate technical competence in abortion.

- The private sector appears to provide a substantial proportion of all abortions, highlighting the need to engage private providers in policy dialogue. Until a true partnership is forged between the public and private sectors, abortion care is likely to remain fundamentally flawed.

\section{Programmes}

- Knowledge of the legal status of abortion is poor. Public information campaigns to educate women, their spouses and other family members about the legal right to abortion must be implemented. Similarly, public and private providers must be better informed of the precise provisions in the MTP Act, including those regarding spousal consent, so they can implement it more effectively.

- Many formal providers use outdated techniques to perform surgical abortions, such as dilation and curettage, which have an increased rates of complications.

Incorporation of modules on electric and vacuum aspiration and medical abortion in professional programmes for gynaecologists and non-gynaecologists alike and in abortiontraining centres is critical. In-service training in these methods is also important for providers who have already completed their training in gynaecology and/or abortion.

- As 70 percent of induced abortions in our sample resulted from unwanted pregnancies, the need for contraception is clear if women are to meet their reproductive intentions. Effort should be made to provide information about and increase access to temporary, as well as permanent, methods of contraception in both the public and private sectors.

\section{cort}

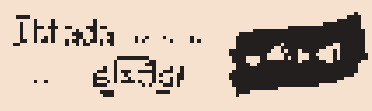

For further information please contact: Population Council Zone 5A, Ground Floor India Habitat Centre Lodi Road, New Delhi 110003 , INDIA Tel: 91-11-2464 2901/2

Fax: 91-11-2464 2903

Email: info@pcindia.org

www.popcouncil.org

\section{References}

1. Chhabra R and Nuna SC. 1994. Abortion in India: An Overview. New Delhi, India: Veerendra Printers.

2. Ganatra BR, Coyaji KJ and Rao V. 1998. Too far, too little, too late: A communitybased case-control study of maternal mortality in rural west Maharashtra. Bulletin of the World Health Organization 76(6): 591-98.

3. Government of India. 1971. The Medical Termination of Pregnancy Act. Act No. 34.

4. International Institute for Population Sciences
(IIPS) and ORC Macro. 2000. National Family Health Survey (NFHS-2), 1998-99: India. Mumbai, India: IIPS.

5. Johnston HB, Ved R, Lyall $\mathrm{N}$ et al. 2001. Post-abortion Complications and their Management: A Community Assessment Conducted in Rural Uttar Pradesh, India. Prime Technical Report \#23. Chapel Hill, USA: Intrah, Prime II Project.

6. Johnston HB. 2002. Abortion Practice in India: A Review of the Literature. Mumbai, India: Centre for Enquiry into Health and
Allied Themes (CEHAT) and Research Centre for Anusandhan Trust.

7. Khan ME, Barge S, Kumar N et al. 1999. Abortion in India: Current situation and future challenges, in Implementing a Reproductive Health Agenda in India: The Beginning, ed. S Pachauri. New Delhi, India: Population Council.

8. Sood M, Juneja Y and Goyal U. 1995. Maternal mortality and morbidity associated with clandestine abortions. Journal of the Indian Medical Association 93(2): 77-79. 